\title{
CONF-9506/0--2
}

\section{Efficiency Modeling and Evaluation of a Resonant Snubber Based Soft-Switching Inverter for Motor Drive Applications}

\author{
J. S. Lai, R. W. Young, and G. W. Ott \\ Oak Ridge National Laboratory* \\ Bldg. K-1220, MS-7280 \\ Oak Ridge, Tennessee 37831-7280 \\ TEL: $615-576-6223$ \\ FAX: 615-576-0279
}

\begin{abstract}
This paper establishes an analytical model for a resonant snubber based soft-switching inverter. The model adopts loss separation method to evaluate losses in individual components. Because of symmetry of the inverter circuit, the developed model is suitable for both singlephase and three-phase inverters. A single-phase inverter has been built and tested with a singlephase induction motor driving a fan load to verify the developed model. The equivalent singlephase induction motor model was curve-fitted from experimental results. The analytical results demonstrated reasonable agreement with the experimental results. The same efficiency evaluation method was then applied to the conventional hard-switching inverter, and the results were compared with that of the soft-switching inverter. The resonant snubber based softswitching inverter shows substantial efficiency improvement over the hard switching PWM inverter, especially in low speed operation.
\end{abstract}

Subject Area: 3 -- Power Converters for Drive Applications

* Prepared by the Oak Ridge National Laboratory, Oak Ridge, Tennessee 37831-7280, managed by Martin Marietta Energy Systems, Inc. for the U. S. Department of Energy under contract DE-AC05-84OR21400.

The submitted manuscript has been authored by a contractor of the U. S. Government under contract No. DEAC05-84OR21400. Accordingly, the U. S. Government retains a nonexclusive, royalty-free license to publish or reproduce the published form of this contribution, or allow others to do so, for U. S. Government purposes. 


\section{Efficiency Modeling and Evaluation of a Resonant Snubber Based Soft-Switching Inverter for Motor Drive Applications}

\section{DIGEST}

\section{Introduction}

Inverter efficiency issues have received attention in power electronics industry. Previous literature indicated that not all the soft-switching inverters are more efficient than the traditional hard-switching sinusoidal pulse-width-modulation (SPWM) inverters [1]. However, the resonant dc link (RDCL) inverter [2,3] and the auxiliary switch commutated resonant pole (ASCRP) inverter $[4,5]$ showed significant efficiency improvement over the hard-switching SPWM inverter without over-voltage or over-current penalty in the switching devices. The ASCRP inverter, requiring two extra dc link capacitors and two auxiliary switches per phase over hardswitching SPWM inverters, can be simplified to a more cost-effective resonant snubber inverter, requiring only one auxiliary switch per phase [6]. The purpose of this paper is to evaluate efficiency of the resonant snubber inverter with analytical models and hardware experiments.

In order to evaluate the inverter efficiency, one must have well-defined component models and inverter switching algorithms. Otherwise, an accurate evaluation can only be obtained by actual tests. However, by making some assumptions and simplifying device models, the analytical model can be fairly applied to inverter efficiency evaluation. For conduction loss evaluation, this paper employs simplified device models: a pure resistor for power MOSFETs, and a voltage source in series with a resistor for Insulated Gate Bipolar Transistors (IGBTs) and diodes [7,8]. For switching loss evaluation, the turn-off loss is considered as a function of the resonant capacitor, and the turn-on loss is neglected [1,3].

In motor drive applications, the inverter efficiency is somewhat different from that of passive loads because the current is filtered by the load, and the output power and power factor are varied with speed and torque conditions. To verify the analytical approach, a single-phase inverter was built and tested with a single-phase induction motor driving a fan load. The equivalent single-phase induction motor model was curve-fitted from experimental results under different speeds. The same efficiency evaluation method was then applied to the conventional hard-switching inverter, and the results were compared with that of the soft-switching inverter. The resonant snubber based soft-switching inverter shows substantial efficiency improvement over the hard switching PWM inverter, especially in low speeds. The analytical efficiency evaluation results demonstrated reasonable agreement with the experimental results. 


\section{Device Models}

\subsection{Conduction Loss Models}

A simplified device model [7] is employed for the conduction loss evaluation. This model assumes the device as a constant voltage drop in series with a nonlinear resistive element during conduction. This nonlinear element contains both resistive and inductive properties. However, due to complexity of computation effort, this paper further simplifies the nonlinear element to a linear resistance in order to derive a closed form solution for the conduction loss. The simplified models for power MOSFET, IGBT, and diode are expressed in (1), (2), and (3), respectively.

$$
\begin{aligned}
& V_{d s}=I R_{d s} . \\
& V_{c e}=V_{t}+I R_{c e} . \\
& V_{a k}=V_{f}+I R_{a k} .
\end{aligned}
$$

Voltages $V_{d s}, V_{c e}$, and $V_{a k}$ represent the on-state voltage drops of MOSFET, IGBT and diode, $V_{t}$ and $V_{f}$ are IGBT and diode voltage drops at the zero current condition, $R_{d s}, R_{c e}$, and $R_{a k}$ are the resistive elements of MOSFET, IGBT, and diode, and $I$ is the device current. This voltage and resistive mode parameters can be obtained from manufacturer's data sheets.

\subsection{Switching Loss models}

There are three switching loss components: device turn-on, device turn-off, and diode reverse recovery. Given a fixed dc bus voltage, the device turn-on and turn-off energies can be represented by (4) and (5), respectively.

$$
\begin{aligned}
& E_{\text {on }}=\left\{\begin{array}{l}
h I \text { for MOSFET } \\
h I^{k} \text { for IGBT }
\end{array}\right. \\
& E_{\text {off }}=\left\{\begin{array}{l}
m I \text { for MOSFT } \\
m I^{n} \text { for IGBT }
\end{array} .\right.
\end{aligned}
$$

Parameters, $\mathrm{h}, \mathrm{k}, \mathrm{m}$, and $\mathrm{n}$, can be derived from the measured data or the manufacturer's data sheet. The diode reverse recovery energy is a function of diode reverse recovery time and the device turn-on rise time and will be expressed in a later section.

\section{Analytical Methods for Inverter Efficiency Evaluation}

\subsection{Resonant Snubber SPWM Inverter}

Figures 1 and 2 show three-phase and single-phase resonant snubber based inverters. The control switches, $S_{a}, S_{b}$, and $S_{c}$, are MOS controlled switches -- either MOSFETs, IGBTs, or 
MOS Controlled Thyristors (MCTs) -- in parallel with reverse blocking diodes. Figure 3 shows operation waveforms in one resonant cycle. Assuming that the diode recovery losses in the resonant branches are negligible, the efficiency evaluation can be obtained by the loss separation approach as described below.

1. Inverter switching device conduction losses $\left(P_{c}\right)$

In the hard-switching SPWM inverter, the device conduction losses of the switching devices and their corresponding anti-parallel diodes are a function of the modulation index and the power factor angle. The modulation index is the ratio of the fundamental output voltage and the based voltage. Assuming that the required inverter output to the motor is the same for both hard- and soft-switching SPWM inverters, it is reasonable to apply the conduction loss model of the hard-switching SPWM inverter to the SRI inverter. Equations (6) (8) express conduction losses for the MOSFET, IGBT, and the anti-parallel diode, respectively [1,7].

$$
\begin{aligned}
& P_{c-M O S F E T}=I_{m}{ }^{2} R_{d s}\left(\frac{\sqrt{3}}{8 \sqrt{\pi}}+\frac{m}{3 \pi} \cos \phi\right) . \\
& P_{c-I G B T}=\frac{1}{2} I_{m} V_{t}\left(\frac{1}{\pi}+\frac{m}{4} \cos \phi\right)+I_{m}{ }^{2} R_{c e}\left(\frac{\sqrt{3}}{8 \sqrt{\pi}}+\frac{m}{3 \pi} \cos \phi\right) . \\
& P_{c-D}=\frac{1}{2} I_{m} V_{f}\left(\frac{1}{\pi}-\frac{m}{4} \cos \phi\right)+I_{m}{ }^{2} R_{a k}\left(\frac{\sqrt{3}}{8 \sqrt{\pi}}-\frac{m}{3 \pi} \cos \phi\right) .
\end{aligned}
$$

Here, $I_{m}$ is the peak load current, $m$ is the modulation index, and $\phi$ is the motor input power factor angle. The total conduction loss for a single-phase MOSFET-based full-bridge inverter can be calculated by $P_{c}=4\left(P_{c-M O S F E T}+P_{c-D}\right)$, and for an IGBT-based three-phase fullbridge inverter is $P_{c}=6\left(P_{c-I G B T}+P_{c-D}\right)$.

2. Inverter device switching loss $\left(P_{S W}\right)$

For the RSI the active device turns on after its anti-parallel diode conducts; theerefor, device turn-on loss is practically zero. The only switching loss is the turn-off loss which is a function of the resonant capacitor, $C_{r}$, and can be expressed in (9) [3].

$$
P_{S W}=\frac{1}{2} \frac{I_{m}^{2} t_{f}^{2}}{24 C_{r}} f_{s}
$$

Here $t_{f}$ is the device turn-off fall time, and $f_{s}$ is the inverter switching frequency.

3. Auxiliary switch conduction loss $\left(P_{c-S r}\right)$

The current flowing through the resonant switch is discrete high frequency half sinusoidal pulses. Its peak magnitude is approximately one per unit of the peak phase current higher than the low frequency phase current, and its duty cycle depends on the resonant pulse width and the 
switching frequency. Giving each phase resonant inductance, $L_{r}$, and each device snubber capacitance, $C_{r}$, one complete positive and negative resonant cycle, $T_{p}$, can be expressed below.

$$
T_{p}=k_{p} \times 2 \pi \sqrt{2 C_{r} L_{r}} .
$$

Note that the resonant pulse is not pure trigular or sinusoidal. It is necessary to simplify the analysis by considering the pulse shape as triangular and multiplying a modification factor, $k_{p}$, into the resonant period to obtain the correct pulse width for one cycle. The value of $k_{p}$ is approximately 1.2. The duty cycle of the auxiliary switch is defined as the product of $T_{p}$ and the switching frequency, $f_{s}$. The conduction loss of each auxiliary branch can be obtained by multiplying the average load current with the auxiliary switch voltage drop and the duty cycle, or

$$
P_{c-S r}=\frac{1}{2}\left(I_{m}+\frac{2 V_{s}}{\pi Z_{r}} Y V_{d s}+V_{a k}+\left(I_{m}+\frac{2 V_{s}}{\pi Z_{r}}\right) R_{a k}\right) T_{p} f_{s}
$$

where $V_{a k-M C T}$ and $V_{a k-D}$ are the device conduction loss model shown in (2), and $Z_{r}$ can be expressed in (12).

$$
Z_{r}=\sqrt{\frac{L_{r}}{2 C_{r}}}
$$

4. Resonant inductor ESR loss $\left(P_{L r}\right)$

The resonant inductor has the same duty cycle as the auxiliary switches but different power loss. Assuming that each inductor ESR is $R_{r}$, the total ESR loss can be obtained by (13).

$$
P_{L r}=\frac{1}{2}\left(I_{m}+\frac{2 V_{s}}{\pi Z_{r}}\right) R_{r} T_{p} f_{s}
$$

\subsection{The Hard-Switching SPWM Inverter}

The efficiency calculation method of the hard-switching SPWM inverter has been well defined in [7]. The switching device and diode conduction losses for each switch-pair are expressed in $(5) \sim(7)$. The instantaneous turn-on and turn-off power losses can be obtained by multiplying switching energies, shown in (3) and (4), with the switching frequency, $f_{s}$. However, with a resonant capacitor across the device, the turn-off loss is approximately zero. To be exact, the turn-off loss can be expressed in (9). The turn-on losses in this case include three components: (1) device turn-on loss without diode reverse recovery part, (2) loss due to diode reverse recovery, and (3) loss due to capacitor discharging. The device turn-on loss can be obtained by averaging the integration of the instantaneous power losses over one fundamental cycle. Equation (14) shows the derivation result in which $p$ is the turn-on energy per ampere. 


$$
P_{s w-o n}=\frac{1}{\pi} f_{s} I_{m} p \frac{V_{s}}{V_{o}} .
$$

The capacitor discharging loss can be derived in (15).

$$
P_{c a p}=\frac{1}{2} C_{r} f_{s} V_{s}^{2} .
$$

The diode reverse recovery loss can be found by

$$
P_{r r}=\frac{I_{m} V_{s}}{2 \pi}\left(1+\frac{3}{8} \frac{t_{r r}}{t_{r}}\right) f_{s} t_{r r}
$$

where $t_{r}$ is the switching device turn-on rise time, and $t_{r r}$ is the diode reverse recovery time.

\section{Performance Evaluation}

Figure 4 shows the experimental setup for a single-phase inverter driving a single-phase fan. In this setup, the most critical instrument is the ac power meter which requires high sampling rate and bandwidth. The inverter switching device is IRFP360 power MOSFET. The auxiliary switch consists of a fast recovery diode, MUR450, and a power MOSFET, IRF740. The auxiliary resonant components are $10-\mu \mathrm{H}$ inductor and $20-\mathrm{nF}$ capacitor. The auxiliary switch can be disabled by the control circuit so that the inverter can be switched between hardand soft- switching modes. With the fan load, the output of the inverter should be invariant between hard- and soft- switchings. However, the noticeable electromagnetic interference (EMI) noises appear on top of the inverter output current when running at the hard-switching mode, while the soft-switching mode has a relatively clean output current, shown in Figure 5(a) and 5(b), respectively.

The tested single-phase induction motor has an auxiliary switch which keeps the auxiliary winding in the circuit when the speed is below half the rated speed, causing a large motor current and overheating the motor stator. In order to avoid over-temperature tripping during experiment, the inverter efficiency was evaluated only when the speed was higher than half the rated speed.

Figure 6 shows the soft-switching inverter efficiency as a function of supply frequency operating from 30 to $70 \mathrm{~Hz}$. Both model predicted and experimental results are plotted for comparison. The discrepancy between the analytical and experimental results gets wider at low speeds, possibly due to incorrect switching loss model. However, the efficiency profile over the entire speed range is far superior to that of the hard-switching operation.

\section{Discussions and Conclusions}

The analytical results of the simplified soft-switching inverter efficiency model used in this paper generally agree with the experimental results. However, in high speeds, the predicted results tend to be lower because the equations do not factor the square-wave operation effects. In 
low speeds, the experimental results for the soft-switching mode tend to be lower because of omissions of the device turn-on loss. The hard switching inverter analytical model shows the same trend but a significant discrepancy in high speeds because the model is only effective for a true SPWM operation.

Consider the efficiency profile of the $15-\mathrm{kHz}$ hard-switching SPWM inverter as the baseline. The resonant snubber based soft-switching inverter shows noticeable efficiency improvement. At the rated speed condition, the inverter shows more than 5 percent efficiency improvement over the hard-switching inverter. At the half speed, the efficiency improvement is about 15 percent. When the speed is higher than the rated speeds, the operation tends to be square-wave operation, and the efficiency improvement of the soft-switching inverter tends to be diminished because the effective switching per cycle is greatly reduced.

With the confirmation of analytical and experimental results, the resonant snubber based soft-switching inverter has demonstrated superior efficiency profile. The efficiency improvement over traditional hard-switching inverters at low speeds is even more promising. There are other benefits obtained from soft-switching besides the efficiency improvement, such as reduction of voltage and current stresses, reduction of heat sink temperature, and elimination of EMI. Future work can be directed to the three-phase soft-switching inverter efficiency verification.

\section{References}

[1] J. S. Lai, R. W. Young, and J. W. McKeever, "Efficiency Consideration of DC Link SoftSwitching Inverters for Motor Drive Applications," Conference Record of IEEE Power Electronics Specialists Conference, Jun. 1994, pp. 1003-1010.

[2] D. M. Divan and G. Skibinski, "Zero Switching Loss Inverters for High Power Applications," Conference Record of IEEE IAS Annual Meeting, Oct. 1987, pp. 627-634.

[3] D. M. Divan, G. Venkataramanan, and R. W. DeDoncker, "Design Methodologies for Soft Switched Inverters," IEEE Trans. on $I A S$, vol. 29, no. 1, Jan./Feb. 1993, pp. 126-135.

[4] W. McMurry, "Resonant Snubbers with Auxiliary Switches," IEEE Trans. on Industry Applications, vol. 29, no. 2, March/April 1993, pp. 355-362.

[5] R. W. DeDoncker and J. P. Lyons, "The Auxiliary Quasi-Resonant DC Link Inverter," in Conference Record of IEEE Power Electronics Specialists Conference, Jun. 1991, pp. 248-253.

[6] J. S. Lai et. al, "A Novel Resonant Snubber Based Inverter" to be published in IEEE Applied Power Electronics Conference, Mar. 1995.

This report was prepared as an account of work sponsored by an agency of the United States Government. Neither the United States Government nor any agency thereof, nor any of their employees, makes any warranty, express or implied, or assumes any legal liability or responsibility for the accuracy, completeness, or usefulness of any information, apparatus, product, or process disclosed, or represents that its use would not infringe privately owned rights. Reference herein to any specific commercial product, process, or service by trade name, trademark, manufacturer, or otherwise does not necessarily constitute or imply its endorsement, recommendation, or favoring by the United States Government or any agency thereof. The views and opinions of authors expressed herein do not necessarily state or reflect those of the 
[7] S. Clemente and B. Pelly, "An Algorithm for the Selection of the Optimum Power Device for the Electric Vehicle Propulsion," in Proceedings of IEEE Workshop on Power Electronics in Transportation, Oct. 1992, pp.129-136.

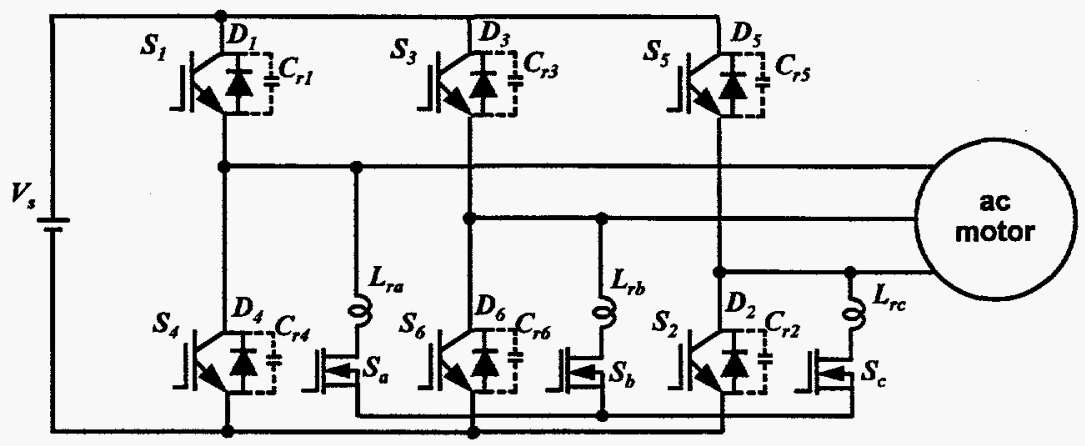

Figure 1: A three-phase resonant snubber based soft-switching inverter.

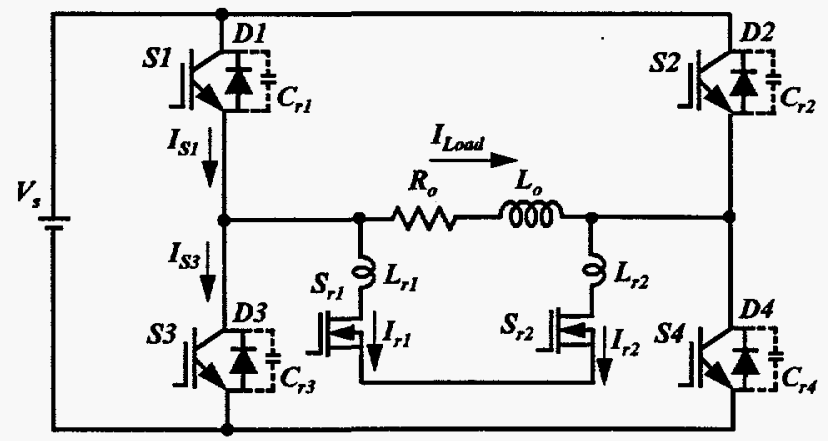

Figure 2: A single-phase resonant snubber based soft-switching inverter

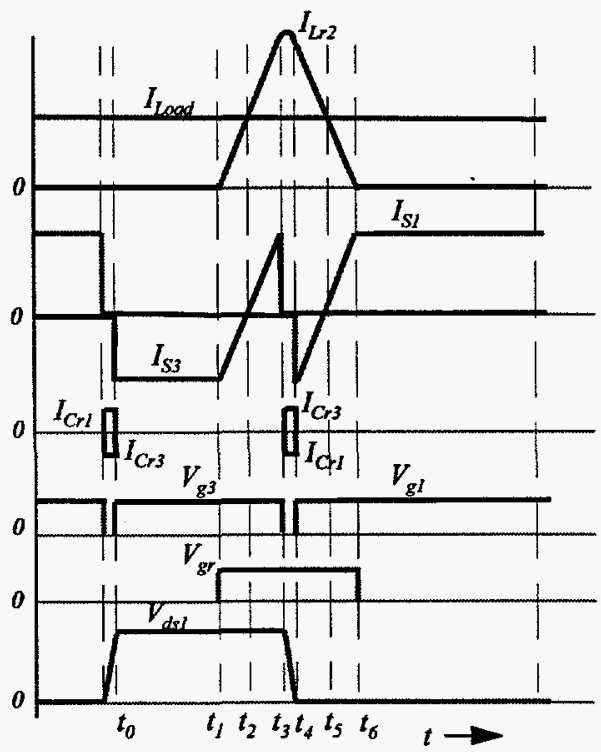

Figure 3: Waveforms showing different operating modes. 


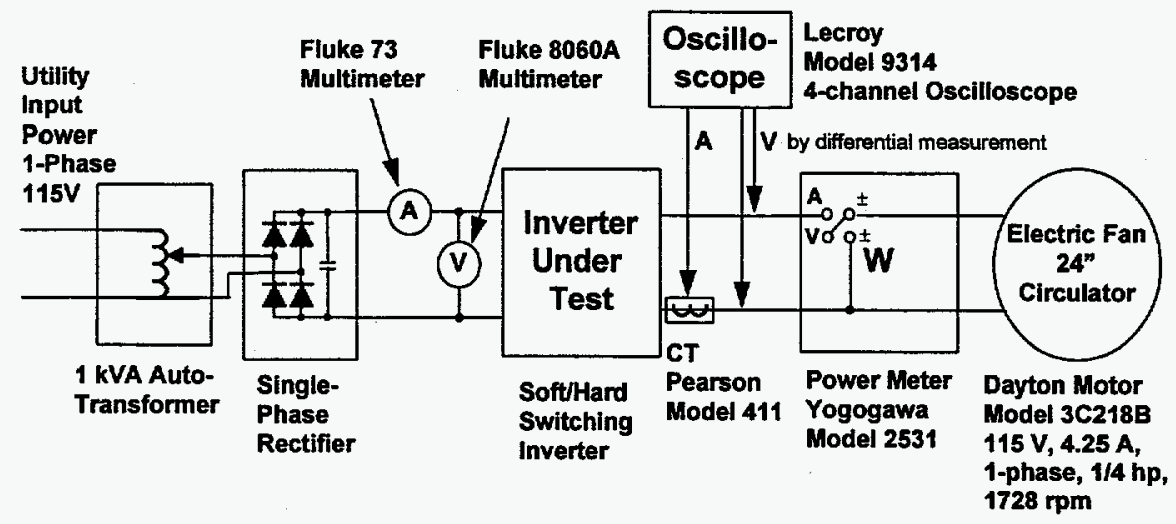

Figure 4: Experimental setup for inverter efficiency evaluation.

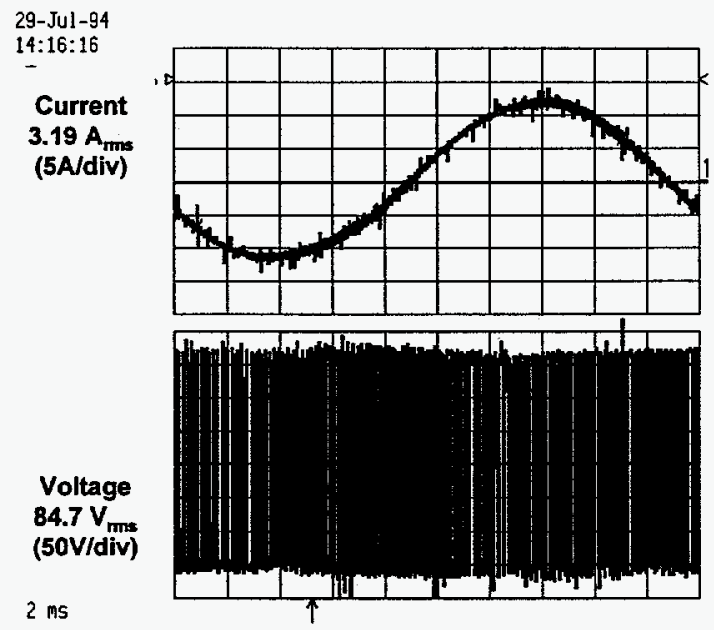

(a) Hard switching

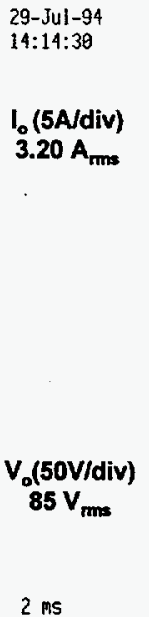

2 MS
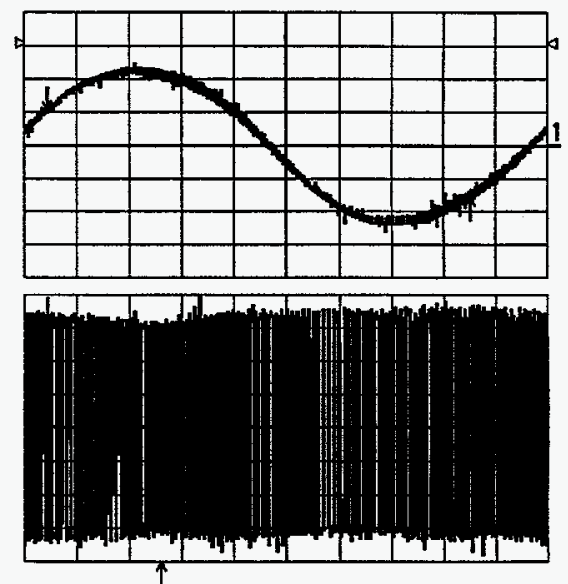

(b) Soft switching

Figure 5: Experimental current and voltage waveforms of SPWM inverter in hard- and softswitching operations.

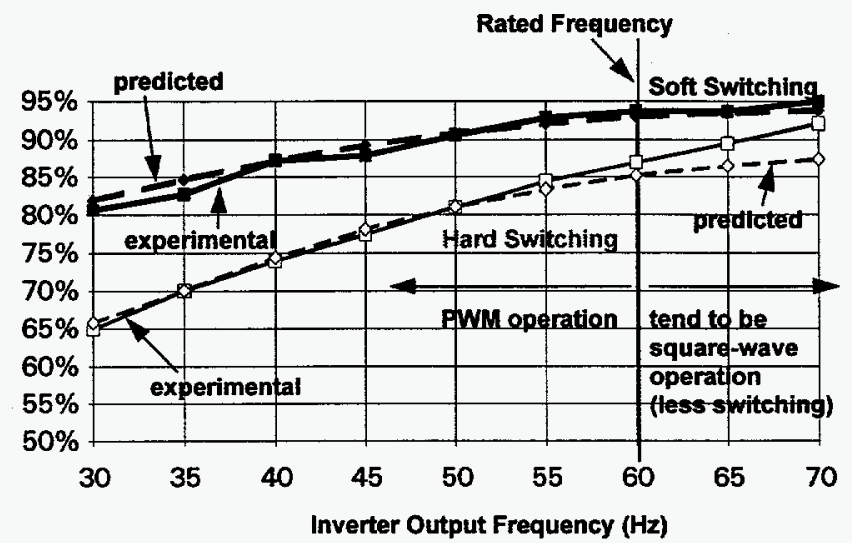

Figure 6: Efficiency as a function of the supply frequency. 